\title{
Characteristics of Polymer Materials with New Smart Utilities
}

\author{
Karolina Głogowska ${ }^{1 *}$, Tomasz Klepka', L'udmila Dulebová ${ }^{2}$ \\ 1 Lublin University of Technology, Nadbystrzycka 36, 20-618 Lublin, Poland \\ 2 Technical University of Košice, Letná 1/9, 04001 Košice, Slovak Republic \\ * Corresponding author's e-mail: k.glogowska@pollub.pl
}

\begin{abstract}
Modern technologies increasingly often rely on the use of intelligent (also known as "smart") materials exhibiting unique utilities and properties. The state of knowledge on intelligent polymers ranges from diagnostic research to a more extensive body of knowledge, combined with the knowledge of the practical methods for manufacturing these materials. On the basis of a review of the subject literature, this paper describes the existing smart polymer materials. It also presents the examples of applications for these new materials. In the further part of the paper, an example of how the concept of smart materials can be used in new polymeric products to influence the selected mechanical properties when the surrounding temperature changes. The new material or the acquisition of different properties was created by undercutting or selecting the correct thickness and type of polymer layer from which the new product is made. The example of own research, apart from their analysis, ends with the conclusions of an applicative nature.
\end{abstract}

Keywords: polymer materials, stimuli-responsive smart polymer materials, mechanical properties

\section{INTRODUCTION}

The materials used in all fields of engineering are one of the fundamental achievements of the human civilization. Over the last few decades, there has been a rapid development in the materials science [1-2]. The availability of a great number of modern construction materials poses new challenges to engineers. They must know the entire spectrum of materials and their potential applications in order to optimally use them in structures. Moreover, these structures must meet certain operational, economic and technological requirements [3]. When working on a project, the designer should conduct a thorough analysis of materials in terms of their mechanical properties, price and technological features. For this reason, the correct selection of materials depends on the knowledge and understanding of the methods for shaping their properties [4], the material constants defining their characteristics, the changes in their properties due to shaping, joining and finishing them, as well as the limitations regarding their use. The basic classification of modern engineering materials is given in Figure 1.

A new group of the so-called "smart materials" has been developed since about 1980. Despite the dynamic development of this type of materials, researchers have not managed to establish an official definition of intelligent materials. Different names have been given to these materials, such as intelligent materials, smart materials, adaptive materials, and even multifunctional materials $[5,6]$. A review of the literature demonstrates that one can distinguish the following intelligent materials: shape-memory metal alloys, piezoelectric ceramic materials, electro- and magnetorheological fluids, magnetostrictive materials, as well as shape-memory polymers, piezoelectric polymers, conductive polymers, ionic gels, polymer composites and nanocomposites.

The new polymeric materials can change their physical or chemical properties, depending on how much they were exposed to external factors, such as temperature, humidity, pressure, magnetic field and electric. The type, chemical 


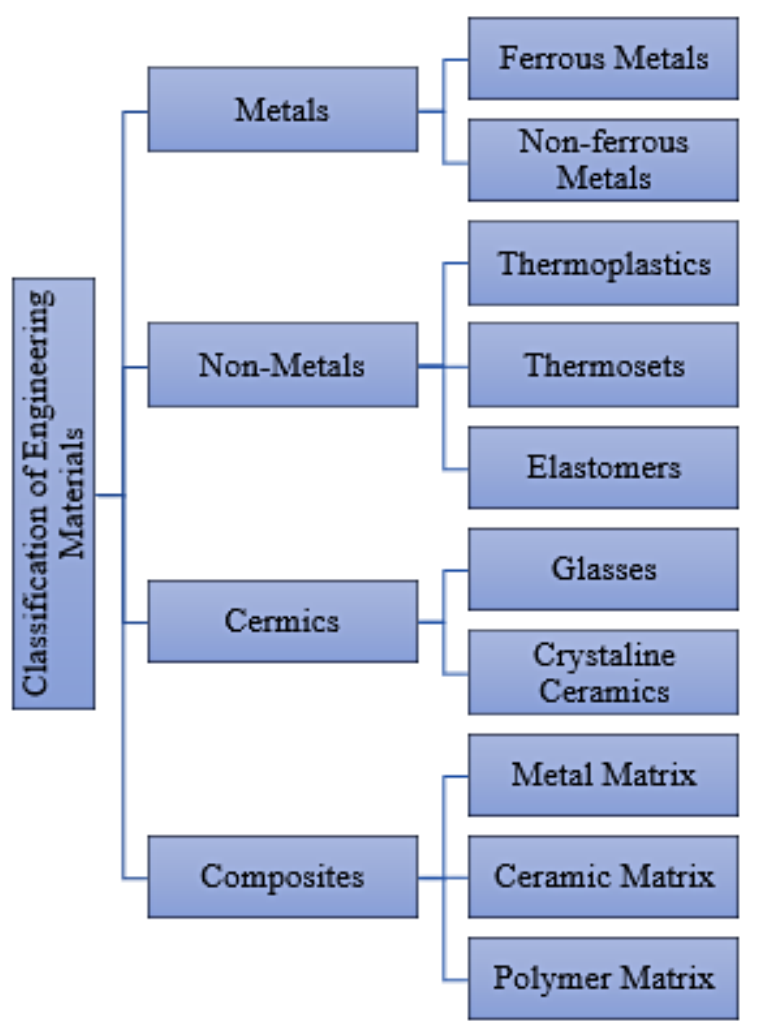

Fig. 1. Classification of engineering materials

composition, structure as well as external factors e.g. during the polymerization process, can cause the materials change their shape, size, color, and the electrical, magnetic or thermal conductivity [7]. The factors causing the structural changes in intelligent polymer materials can be divided into three groups (Fig. 2): physical (temperature, ultrasounds, light, mechanical stresses), chemical ( $\mathrm{pH}$ and ionic strength) and biological (enzymes) [8].

The following part of the work presents a short review of the literature on shape memory polymers (SMP). The mechanism and course of the shape-memory effect in this type of materials was characterized. Shape-memory polymers (SMPs) have gathered attention from not only academic, but also industrial researchers, because of their usefulness and functionality. The polymers with shape memory present a significant prospects for a variety of applications.

The design of intelligent materials is based on the knowledge of both materials science and exact sciences (physics, chemistry, mathematics). The development of intelligent materials is aimed at creating the materials with specified functional features. It is claimed that the materials of this type are crucial for the development of many fields of technology, in advanced and everyday technologies alike. Smart materials can be used alone or as components of other construction materials. Many research centers and industrial research and development units in Poland and all over the world are conducting the experiments and research focused on the production and practical applications of new materials.

Smart polymers (SP) and their applications are becoming increasingly significant. Over the twenty to thirty years one could witness an explosive growth in the subject [9]. Intelligent polymer materials can be classified depending on their properties, as shown in Figure 3.

\section{Shape memory polymer}

There is currently an active search for shape memory polymers as, unlike metals with shape memory, they are lightweight, cheap, resistant to large deformations, have good shape recovery capabilities, are easy to process and program repeatedly, as well as allow controlling their response time to stimulus and time of use. Furthermore, it is possible to dye them and by slight modification of their composition the temperature of shape change can be affected. However, compared to alloys, polymers are characterized by low stress transfer levels. Figure 4 shows the schematic representation of four steps of the shape memory effect in SMPs [10-16]. 


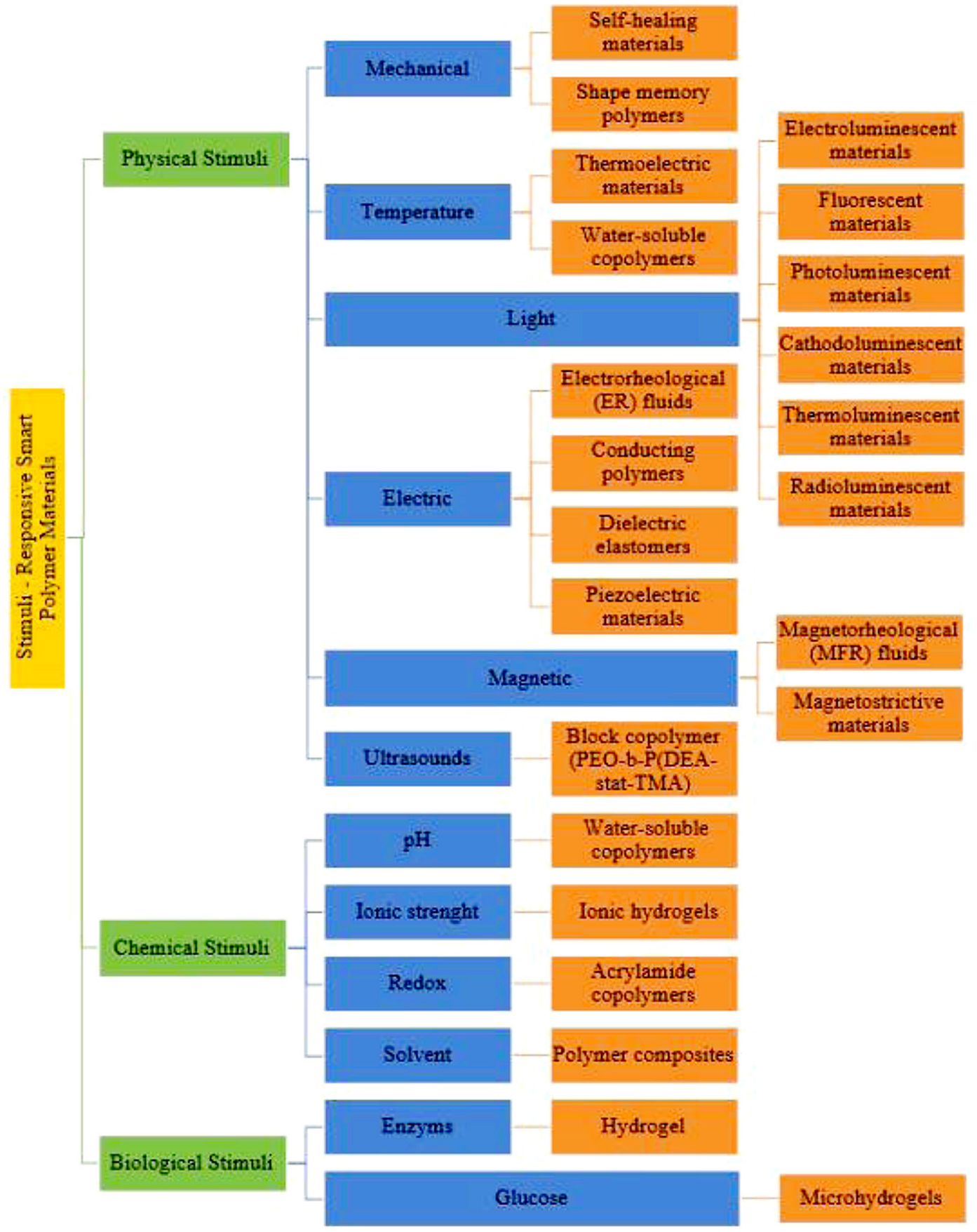

Fig. 2. Stimuli-Responsive Smart Polymer Materials

\section{Example of a creation of smart utilities in polymeric material composition}

The use of shape memory polymers in new technical solutions requires determining the parameters of the ability to recover the shape, adjust the shape, as well as examining their properties under various working conditions. The subject of the study was a beam made of polymeric material made of a single polymer and two polymers. In the latter case, both materials at the phase boundary were coherently connected. A traditional polymer and new polymer compositions were used to make both the samples and individual layers. The aim of the study was to determine the changes in the displacement value of a movable beam element in relation to a fixed straight section under conditions of ambient temperature change, in regards to the type of material, thickness of wall and of individual layers of the tested samples. 


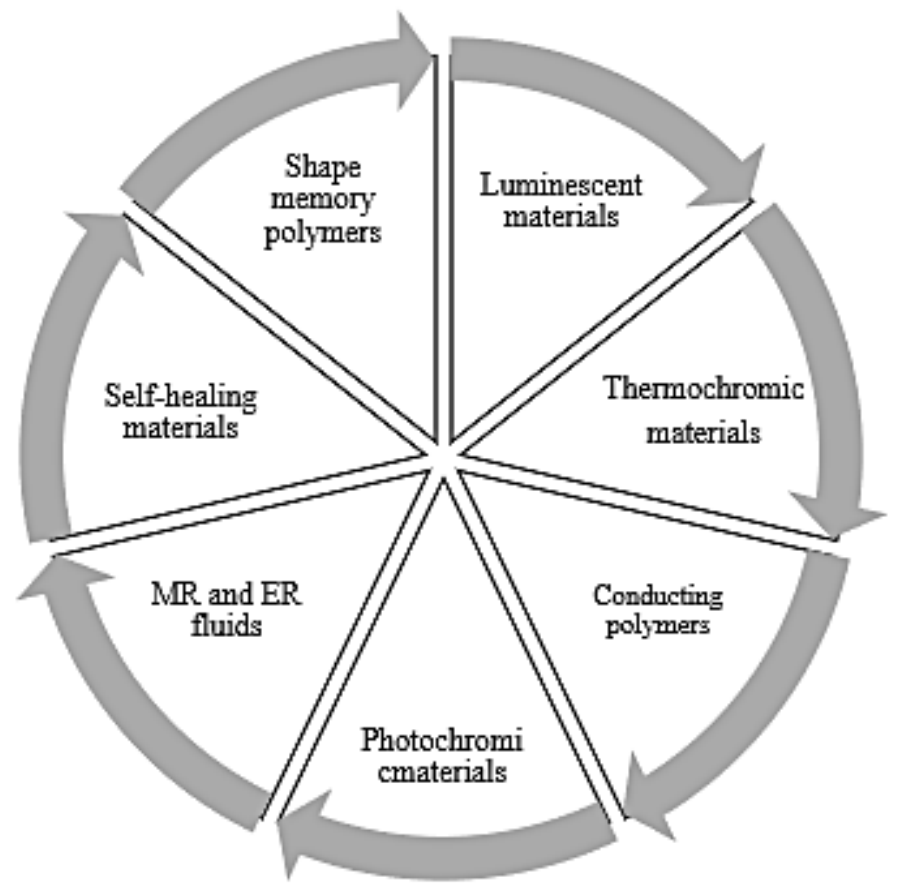

Fig. 3. Classification of smart polymer materials, depending on their properties

\section{MATERIALS}

A well-known and frequently used thermoplastic polypropylene (PP) material with the trade name Malen P J-400 produced by Petrochemia Płock S.A. was used in the research. The basic application of this material is the production of injection-molded products for technical applications and consumer goods, e.g. household appliances, garden furniture, disposable syringes, details for the automotive industry, etc. In order to make an additional layer, a polymeric composite obtained from a mixture of polypropylene with an additive reducing the plasticizing temperature was used. This material exhibited the following properties: density at $21^{\circ} \mathrm{C}-1130 \mathrm{~kg} / \mathrm{m}^{3}$, tensile strength - $11 \mathrm{MPa}$, flexural modulus - $350 \mathrm{MPa}$, elastic modulus - $175 \mathrm{MPa}$, and characteristic optimum activation temperature $-65^{\circ} \mathrm{C}$.

\section{Test site and methodology}

Arburg's Allrounder 320C twin-socket screw injection molding machine was used to produce the polypropylene samples for the production of beam-shaped samples. The mold used had a flow system with cold channels. In the first stage polypropylene was injected, whereas in the second one, after turning the tool with the injection point, the second type of plastic (a polymer composite) with an additive reducing the plasticizing temperature was injected again. Three types of samples were used for experimental studies: the first one was made of a single plastic (polypropylene and a composition of polypropylene with an additive) and the next two were a combination of two materials differing in layer thickness. Additionally, a groove was made on the samples using the cold pressing method (Fig. 6). The polymers and their thermal properties were researched using differential scanning calorimetry (DSC). The Netzsch DSC 204 calorimeter (Germany) in a dynamic mode was used to obtain calorimetric measurements. Dynamic scans were performed at a heating rate of $10 \mathrm{~K} \mathrm{~min}^{-1}$, with temperatures ranging from room temperature to a maximum of $550^{\circ} \mathrm{C}$ in the atmosphere of nitrogen $(30 \mathrm{ml} \mathrm{min}-1)$. The sample mass was $\sim 10 \mathrm{mg}$. As a reference, an empty aluminum crucible was used. The displacement tests were carried out with the use of a thermal chamber with a range of temperatures from 0 to $300^{\circ} \mathrm{C}$. The temperatures at which the deformation / displacement of the samples (Fig. 5) was observed ranged from $20^{\circ} \mathrm{C}$ to $100^{\circ} \mathrm{C}$, respectively.

\section{Results of the research and their analysis}

The examples of DSC thermograms for polypropylene and polypropylene compositions with additive during cooling and heating are presented 


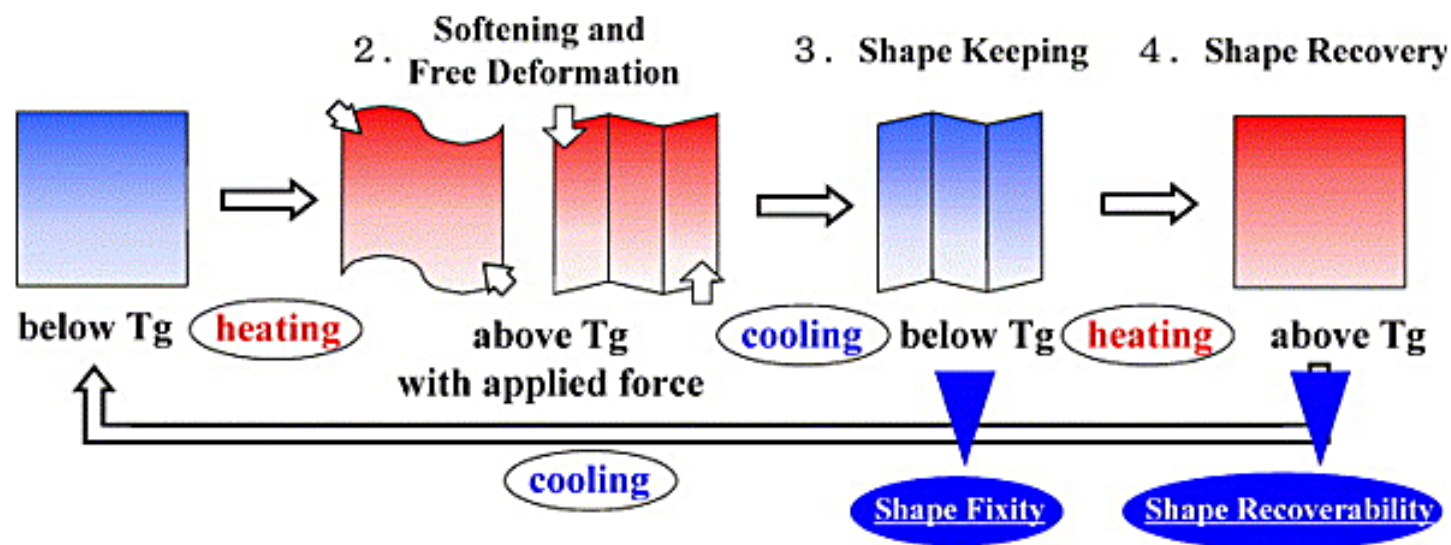

Fig. 4. Four steps of the shape memory effect [14]

in Figures 6 and 7. Endothermal peak on the melting curve corresponding to the melting point of polypropylene occurs at $115.9^{\circ} \mathrm{C}$ and the enthalpy change in the melting process is $122.6 \mathrm{~J} / \mathrm{g}$ (Fig. 6).

The DSC curve is presented in Figure 7. On the curve, two endothermic effect are visible. First endothermic effect (temperature range: $50-$ $90^{\circ} \mathrm{C}$; a maximum of $71^{\circ} \mathrm{C}$ ) is probably connected with a softening polymer effect. The second endothermic effect in the range $380-460{ }^{\circ} \mathrm{C}$ (the maximum of $427.9^{\circ} \mathrm{C}$ ) corresponds to the total thermal degradation of the aromatic part of the studied polymer [17, 18].
Figure 8 shows the specimens that have been heated at $60^{\circ} \mathrm{C}$ and $100^{\circ} \mathrm{C}$. The graphical displacement of the tested samples is shown in Figure 9. A constant temperature increase and mechanical cold plastic deformation did not affect the samples made of pure polypropylene in any way. In the samples consisting of two layers of materials, a significant displacement of the movable arm of the beam with arm L1 was observed.

The changes in the displacement values of the moving part of the sample for mono-polymer and duo-polymer, differing in the layer thickness are shown on diagrams 10 and 11 . While
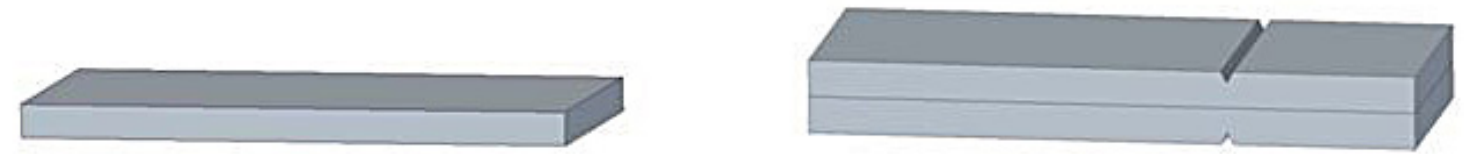

Fig. 5. General appearance of the samples used in the tests

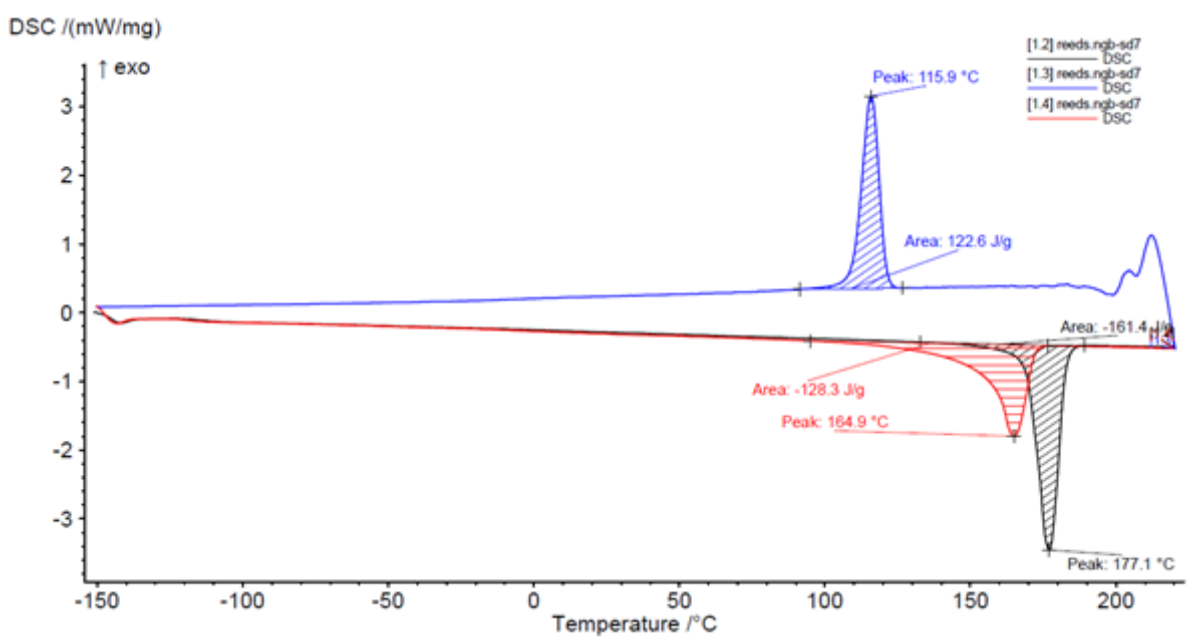

Fig. 6. DSC thermogram: polypropylene: 1 - melting curve, 2 - crystallization curve 


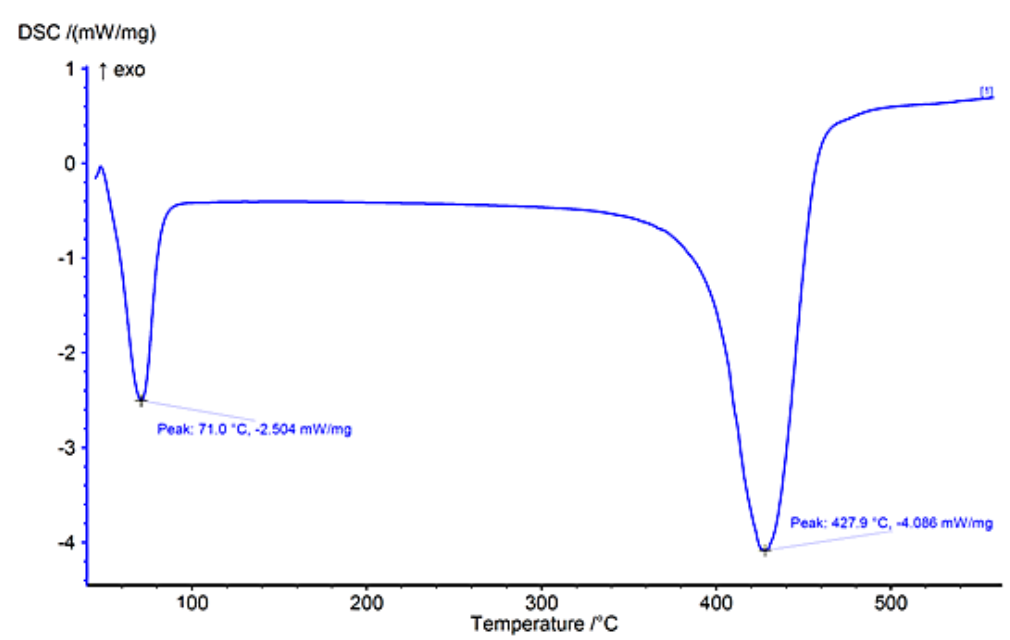

Fig. 7. DSC thermogram of a polymer composition obtained from a mixture of polypropylene with a plasticizing temperature reducing additive
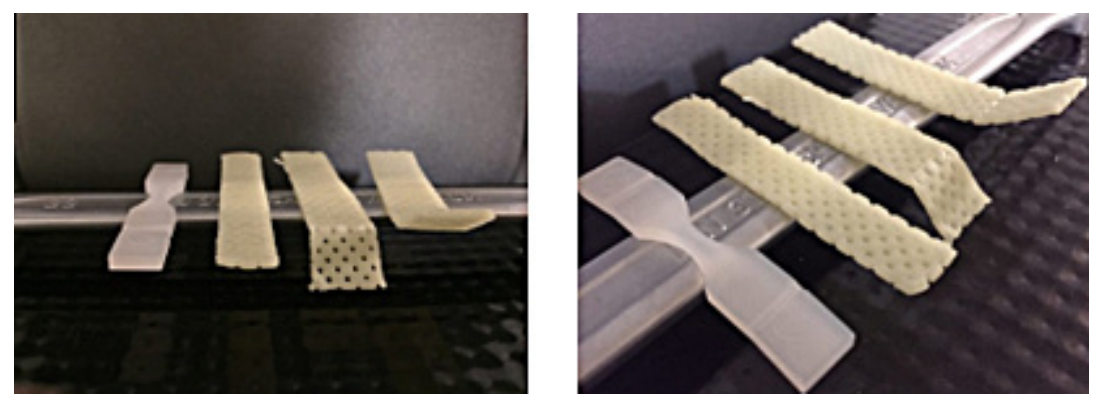

Fig. 8. The appearance of the samples used in the test after being heated at $60^{\circ} \mathrm{C}$ and $100^{\circ} \mathrm{C}$

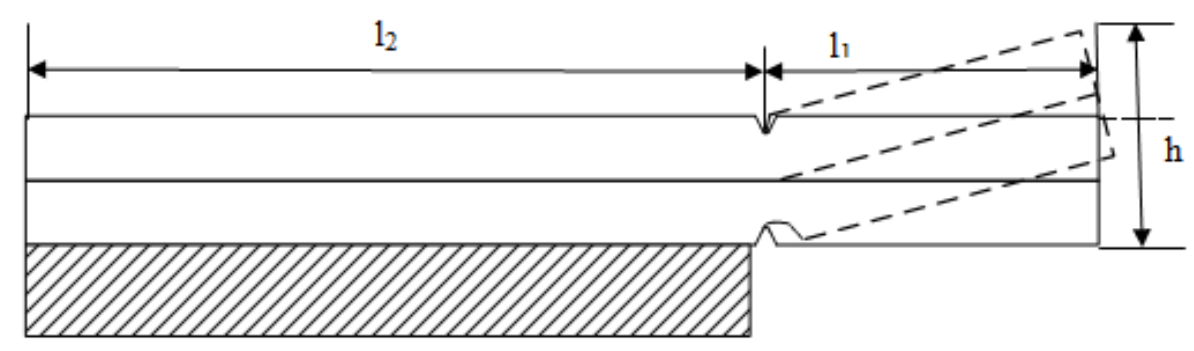

Fig. 9. A diagram presenting the displacement of the movable arm in relation of the rest of the beam

analyzing the obtained results, it can be stated that the assumed smart features of the new product were obtained. The samples consisting of single layers of two different plastics behaved differently. In order to gather the displacement of the sample arm from polypropylene, a temperature of about $93^{\circ} \mathrm{C}$ was needed, while in the case of polypropylene copolymer with touch decreasing the plasticization temperature - a temperature of $59^{\circ} \mathrm{C}$ was sufficient.

In the case of the products with the layers made of two different materials, it was noticed that the layers of smaller thickness caused greater deformation, at lower temperatures
- displacement of the L1 arm in a shorter time. The maximum displacement value for $\mathrm{PP}+\mathrm{PP}$ combination with additive was observed in the tested samples at the temperature of $72^{\circ} \mathrm{C}$ and in the case of greater thickness, the value of the temperature at which the highest displacement was obtained was $100^{\circ} \mathrm{C}$.

\section{CONCLUSIONS}

The development of intelligent materials is aimed at creating the materials with specific new functional features. The engineers and designers 


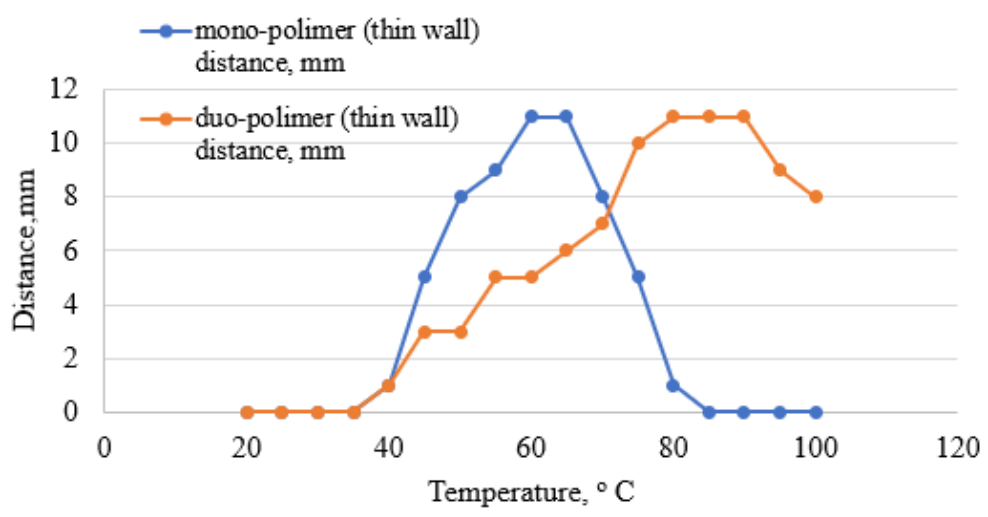

Fig. 10. Diagram of change in displacement value for mono-polymer (thin wall) and duo-polymer (thin wall) in relation to temperature

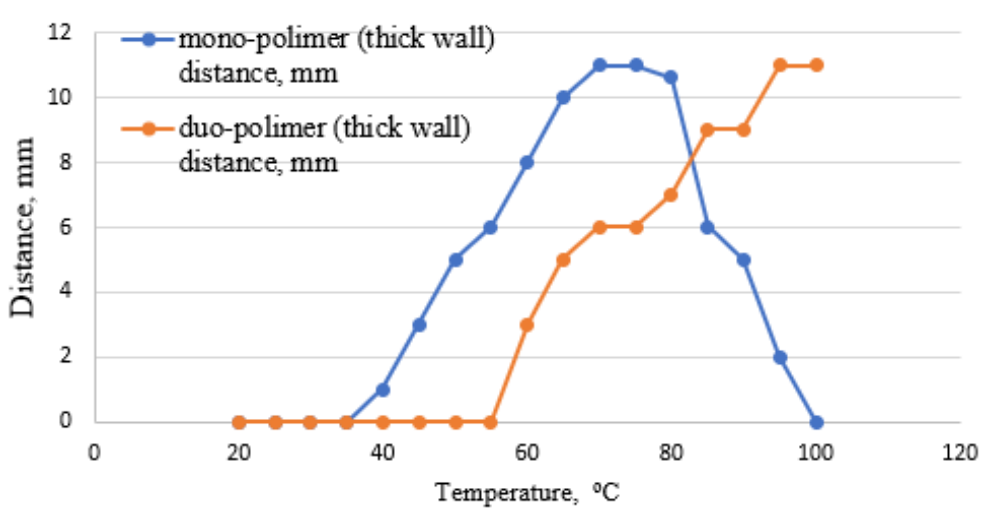

Fig. 11. Diagram of change in displacement value for mono-polymer (thin wall) and duo-polymer (thin wall) in relation to temperature

can use these materials in a wide spectrum of applications. A further increase in the number of "smart" devices made of "smart" materials that will be increasingly tailored to the needs of users by making them more functional and user-friendly can be expected in the coming years.

On the basis of the research above, the following conclusion can be drawn. The materials presented in the research can be modified relatively easily to obtain "smart material" features. In this case, the movable and fixed arm beam can be used for switches or contactors where the use of traditional contactors made of metal components that react to the temperature changes is not possible.

By selecting the right materials and composing their layers, as well as the length of the arm of the switch and disconnected, it is possible to precisely adjust the temperature value at which a specific displacement value is obtained. When the temperature changes, the material reacts in a defined way, triggering a switch-off or switch-on mechanism.

\section{REFERENCES}

1. Garbacz, T., Surface free energy of extruded polymer compositions. Physicochem. Probl. Miner. Process. 2019, 55(6), 1509-1516.

2. Janusz, S., Majewski, Ł., Puszka A. Modern Biodegradable Plastics - Processing and Properties: Part I. Mater. 2020, 13(8), 1-22.

3. Tor-Światek, A. Evaluation of the effectiveness of the microcellular extrusion process of low density polyethylene. Maintenance and Reliability. 2013, 15(3), 225-22

4. Jachowicz, T. Gajdoš, I. Effect of natural ageing on some properties of oxybiodegrading agentcontaining polypropylene products. Przem. Chem. 2014, 93(11), 1983-1885.

5. Yu, X.; Chen, L.; Zhang, M.; \& Yi, T. Low-molecular-mass gels responding to ultrasound and mechanical stress: towards self-healing materials. Chem. Soc. Rev. 2014, 43(15), 5346-5371.

6. Wojciechowski, S.; Boczkowska, A. Intelligent materials 2004. Arch. Metall. Mater. 2004, 49(4), 723-734. 
7. Stuart, M.A.C.; Huck, W.T.S.; Genzer, J. et al. Emerging applications of stimuli-responsive polymer materials. Nat Mater. 2010, 9, 101-113.

8. Kumar, A.; Srivastava, A.; Galaev, I. Y. et al. Smart polymers: Physical forms and bioengineering applications. Prog. Polym. Sci. 2007, 32(10), 1205-1237.

9. Lin, G.; Chang, S.; Kuo; C. H. et al. Free swelling and confined smart hydrogels for applications in chemomechanical sensors for physiological monitoring. Sens Actuators B Chem. 2009, 136(1), 186-195.

10. Jiang, H. Y.; Kelch, S.; Lendlein, A. Polymers move in response to light. Adv. Mater. 2006, 18(11), 1471-1475.

11. [11] Yang, B.; Huang, W. M.; Li, C.; Li, L. Effects of moisture on the thermomechanical properties of a polyurethane shape memory polymer. Polym. 2006, 47(4), 1348-1356.

12. Tobushi, H.; Hayashi, S.; Hoshio, K.; Miwa, N. Influence of strain-holding conditions on shape recovery and secondary-shape forming in polyurethane-shape memory polymer.
13. Leng, J.; Lu, H.; Liu, Y.; Huang, W. M.; Du, S. Shape-memory polymers - a class of novel smart materials. MRS Bull. 2009, 34(11), 848-855.

14. Ohki, T., Ni, Q. Q., Ohsako, N., \& Iwamoto, M. Mechanical and shape memory behavior of composites with shape memory polymer. Compos. PT A- Appl Sci. Manuf. 2004, 35(9), 1065-1073.

15. Ratna, D.; Karger-Kocsis, J. Recent advances in shape memory polymers and composites: a review. J. Mater. Sci. 2008, 43(1), 254-269.

16. Ni, Q. Q., Zhang, C. S., Fu, Y., Dai, G., \& Kimura, T. Shape memory effect and mechanical properties of carbon nanotube/shape memory polymer nanocomposites. Compos. Struct., 2007, 81(2), 176-184.

17. Podkościelna, B., Lipke, A., Majdan, M., Gawdzik, B., Bartnicki, A., Thermal and photoluminescence analysis of a methacrylic diester derivative of naphthalene-2,7-diol, J. Therm. Anal. Calorim. 2016, 126, 161-170.

18. Fila, K., Grochowicz, M., Podkościelna, B. Thermal and spectral analysis of copolymers with sulphur groups, J. Therm. Anal. Calorim. 2018 133(1), 489-497. 